\title{
MEWLIDÊ MELA EHMEDÊ XASÎ DE \\ TESÎRÊ MEWLIDÊ MELA HUSEYNÊ BATEYî
}

\section{Mehmet YERGIN*}

\begin{abstract}
KILME
Na xebate de Edebiyato Klasîk yê Kurdan de di mewlidê ke bi lehçeyanê kurdkî ra kurmanckî û zazakî de tewr verê nusiyayê, ameyê pêveronayîş. No pêveronayîş de waziyayo ke Melayê Xasî, ke nuştişê mewlidê Melayê Bateyî ra nêzdiyê di sey serrî dima mewlido zazaki yo tewr verên nuşto, nê mewlidî de tesîrê Melayê Bateyî û mewlidê ey esto yan çin o, bêro tesbît kerdene.

Na xebate de verê cû derheqê nê di muelifanê erjayeyan û eserê înan ê tewr muhîman, ke mewlid î, bi kilmeyî malumatî ameyê dayene. Dima nê mewlidî bi dore, hetî şeklî ra û hetê muhtewa ra ameyê wekenitiş. Bi no hawa ma kerdo ke her di eseran de hetê ke pêmanenî û hetê ke cêra ciyayî, bêrê tesbît kerdene. Û peynî de ameyo tesbît kerdene ke Mewlidê Mela Ehmedê Xasî de tesîrê mewlidê Mela Huseynê Bateyî esto.
\end{abstract}

Çekuyê Serekeyî: Melayê Bateyî, Melayê Xasî, Edebiyato Klasîk, Mewlid.

\section{THE EFFECT OF MOLLAH HUSEYN-I BATES MAWLID ON THE MOLLAH EHMED-î XASÎS MAWLİ}

\begin{abstract}
Classical Kurdish literature in this study were compared to the first mawlid written in Kurdish Kurmancî and Zazakî dialects. In this comparison, after nearly two hundred years from Mollah Batî wrote the Kurmancî mawlid, Xasî of Mollah who wrote zazakî mawlid, Mollah Batî and it was tried to determine the effect of any remaining mawlid.

* Wendekarê Unîversîteyê Artuklu Yê Mardînî, Enstîtuyê Ziwanê Ke Tirkiya De Ciwiyenê, Qismê Ziwan û Kulturê Kurdan. Mardîn, Tirkiya E-mail: yergin21 @ hotmail.com

Student, Mardin Artuklu University, Institute of Living Languages in Turkey, Kurdish Language and Culture Departmant. Mardin, Turkey
\end{abstract}


Brief information about this study, the first and most important works of these two precious author mavlid are given. After the mawlid has been analyzed in terms of the order form and content. Thus, we have attempted to determine the aspect that are similar and different in both works. Ultimately, we have determined effect of Mollah Hüseynê Bateyî on Mollah Ehmedê Xasî’s mawlid.

Keywords: Mollah Bateyî, Mollah Xasî, Classical Literature, Mawlid.

\section{DESTPÊK}

Mewlid, edebiyato klasîk yê Îslam de yew bêjê edebiyatî yo. Ê nuştêyê menzûmî ke derheqê biyayîşê pêxemberê muslumanan Hz. Muhemmedî (s) de, cuya ey, mûcîzeyanê ey û meseleyanê derheqê ey de bi terzê mesnewî ameyê nuştiş ra mewlid vajêno. Senî ke kurdkî de mewlidî ameyê nuştiş, ziwananê bînan yê sey 'erebkî, tirkî û sewbîna ziwanan de zî mewlidî nusiyayî.

Edebîyato klasîk yê kurdkî de mewlido tewr verên Mewlidê Mela Huseynê Bateyî (Mewlûda Kurmancî) yo. No mewlid seserra 18. de hetê Melayê Bateyî ra, lehçeyanê ziwanê kurdkî ra, bi lehçeyê kurmanckî ameyo nuştiş. Lehçeyê zazakî de zî Mewlido tewr verên, mewlidê Mela Ehmedê Xasî, Mewlidu'n-Nebiyyi'l-Qurayşiyyi (Salawâtullahi Aleyhi Fi'lBukreti we'l-Aşiyyi) yo, ke no mewlid eynî wext de destpêkê edebîyatê nuştekî yê zazakî hesibîno.

Na xebata xo de ma waşt ke ma mewlidê kurmanckî û mewlidê zazakî bidê pêvero ke eceba bêntareyê nê her di mewlidan de hetê hevparî/ortaxî û hetê ciyayî çi yê? Mewlidê Melayê Xasî de tesîrê Melayê Bateyî û Mewlidê ey çi yo? Ma cewabê nê her di persan Mewlidê Bateyî û Mewlidê Xasî de cibigêrî.

Ez wazena ke cigêrayişê cewabê nê di persan de, di hetan ra nê di eseranê erjayeyan ser o vindera. Heto yew hetê şeklî ra, heto bîn zî hetê muhtewa ra yo. La heme çî ra ver lazim o ke ma verê cû nê di erjê kurdanê ke wayirê nê her di esaranê erjayeyanê bişinasnî û bi kilmeyî behsê cuya înan bikerî. Dima ma do mewlidê kurmanckî û mewlidê kirdî (zazakî) ser o vinderî. 


\section{EDEBIYYETÊ KURDKÎ DE MEWLID Û MEWLIDNUŞTIŞÎYE}

Çekuya "mewlid"î çekuyêka erebkî ya û manaya xo ya çekuyî́; biyayîş, mayaxorabiyayîş, cayê biyayîşî û wextê biyayîşî yo. Manaya mewlidî ya istilahî zî; edebiyatê Îslamî de, ê eserê menzûmî ke mijarê înan o sereke biyayîșê pêxemberê musulmanan Hz. Muhemmed (s) o, la hetê nêy de xeleqnayîşê nurê ey, hedîseyê ke biyayîşê ey ra ver ameyê meydan, mûcîzeyê ke bi biyayîşê ey ameyê meydan, hedîseyê ke pêxemberîya ey ra ver û pêxemberîya ey ra pey ameyê meydan, hedîseyê mîracî, wefatê ey ûsn. hedîseyan ser o nusiyayî yê. Metnê mewlidan, zafene şeklê nezmî yê mesnewî de nusiyayê. (Trasşç1, 2012: 501)

Edebiyatê Kurdkî de mewlido ke tewr verî nusiyayo, mewlidê Mela Huseynê Bateyî yo, ke no mewlid miyanî şarî de bi nameyê "Mewlûda Kurmancî" meşhûr biyo. Mewlidnameyê Melayê Bateyî, tarîxê edebiyatê kurdî de esero yewin o ke no warî de nusiyayo. Nuştişê nê mewlidî ra ver, miyanê kurdan de mewlidê erebkî waniyayêne. La mewlidê Melayê Bateyî ra pey hinî mewlidê kurmanckî cayê mewlidê erebkî girewto. Zaf şaîrê kurdî, hetê mewlidî ra, ke edebiyatê klasîkî de bêjêk o, bin tesîrê Melayê Bateyî û mewlidê ey de mendî. Coka Melayê Bateyî ra pey, zaf kesan mewlidê kurmanckî hetta mewlidê zazakî nuştê. (Adak, 2013: 249-250)

Hayrettin Kızıl, meqaleya xo ya ke nameyê aye "Diyarbakır ve Çevresinde Yazılmış Mevlitlerin Konularına Göre Tasnifi Denemesi" (Goreyê babetanê înan cerebnayîşê tesnîfkerdişê mewlidî ke Diyarbekir û nordorê ey de nusiyayî) yo de mewlidê kurdkî kerdî di qismî. Qismo yewin de ê mewlidê ke bin tesîrê Melayê Bateyî de nusiyayê, qismo diyin de zî mewlidê ke bê tesîrê Melayê Bateyî nusiyayî ser o vinderto. (Kız1l, 2012: 129) Seba ke no mewzu teberê xebata ma de yo, ma nê mewzuyê ser o nêvindenî. Tena mewlidê ke heta ewro bi ziwanê kurdkî (kurmanckî, zazakî) nusiyayê û weşaniyayî û ma pê hayîdar biyî, bi nuştoxanê înan reyde, ma do cêr de rêz bikî.

Mewlidê ke nusiyayê la nêweşaniyayê zî estê. La seba ke nêweşaniyayî hewce nêkeno ke ma tiya de înan ra behs bikerî.

\section{Mewlıdê Kurmanckî}

Edebîyatê klasîk yê kurdkî de Mewlidê Melayê Bateyî ra dima zaf mewlidê kurmanckî nusiyayî. Nînan ra êyê ke ma nameyê înan û nameyê nuştoxanê înan tesbît kerdî cêr de rêz biyî. La ez bawer kena mewlidê ke ma nêeşkayî tesbît bikerî zî estê. Çunke hima zî 
mewlidnuştişiye dewam kena. La seba ke no mewzû teberê xebata ma de yo, ma tena bi dayîşê nameyê mewlidê ke ma tesbît kerdî bese kenî. Nê mewlidî zî nêyî:

1- Mela Huseynê Bateyî, Mevlid-i Nebî Aleyhi's-Selâtu we's-Selâm (Mewlûda Kurmancî)

2- Şêx Muhemmed Emin el- Hayderî, Mewlida Neb̂̂

3- Mela Zahid Kardeşlîk, Mevlûd-i Şerif

4- Mela Bedreddin, Mewlûda Kurdî Bi Zimanê Gundî

5- Mela Ali bin es-Seyyid Abdurrahman, Haza Kitab Ava Heyat

6- Mela Muhammed Ali Fudeylî, Mewlûda Şerîf

7- M. Mustefa yê Mela Aliyê Êzdarî, Mewlida Şerîf Ji Ewwel Heta Axir Rehber-i Xelasî Hz. Muhammed (SAV)

8- Molla Muhemmed el-Xursî (Ekinci), Nezma Şêrîn Der Mewlid û Sîreta Resûlê Emîn

9- Mela Silêman Kurşun, Mewlida Pêxember

10- M. Burhan el-Hedbî, Mewlida Kurdî Bi Şêwaza Hedbî

11- Şêx Muhemmed Sîracuddîn, Durra Birincî Mewlûda Kurmancî

12- Mela Ehmed Nas, Fêkiyê Narîncî Mewlûda Kurmancî

13- Feyzullah Erzen (Seyyid Feyzullah Fındikî), Hate Sefadi Mewlidî Mustafa

14- Feyzullah Erzen (Seyyid Feyzullah Findıkî), Gulê Narîncî Mewlidê Kurmancî

15-Muhammed Şerif el-Batırgizî, Risâletu'l-Usûl fì Mevlîdi'r-Rusûl

16- Mele Şewqî, Mevlidi'n-Nebî Aleyhi's-Salâti ve's-Selâm

17- Mele Ahmed, Mevlidi'n-Nebî Aleyhi's-Salâti ve's-Selâm

18- Feyzullah Haznevî, Rasûli bî Hember

19- Mela Abdurrahman Becirmenî, Mevlid-i Muhammed Mustafa

20-Mele Hasan, Mevlidü'n-Neb̂̂

21-Şeyh Muhammed Mehdî, Mevludê Kurmancî

22- Mele Abdurrahman Harhûrî, Mevlûdê Siyer

Her çend zaf mewlidê kurmanckî nusiyayî zî, miyanê nê mewlidan de mewlido ke miyanê şarî de tewr zêde rexbet diyo û miyanê heme kurdan de nam dayo mewlidê Mela Huseynê Bateyî yo. 


\section{Mewlıdê Zazakî}

Zazakî de zî henda kurmanckî nêbo zî, goreyo ke edebiyatê nuştekî yê zazakî erey dest pêkerdo, mewlidî ke nusiyayî tayn niyê. Nînan ra êyê ke çap biyî yan zî tay kovare û keyepelan de weşaniyayî cêr de rêz biyî. La seke cor de qismê mewlidê kurmanckî de ma vatibi, zazakî de zî mewlidnuştişiye hima dewam kena. Coka mewlidê ke hima çap nêbiyê û nêweşaniyayê zî estê. Labelê seba ke teberê babeta ma de yê, ma do înan ser o nêvinderî. Mewlidê zazakiyê ke heta ewro bi hawayêk weşaniyayê nê yê:

1- Mela Ehmedê Xasî, Mewlidu'n-Nebiyyi'l-Qurayşiyyi (Salawâtullahi Aleyhi Fi'lBukreti we'l-Aşiyyi)

2- Osman Efendiyo Babij, Biyîşêe Pêxemberî (Mewlûda Nebî)

3- Mela Mehmed Elî Hunij, Mewlidî Peyxemberî

4- Mela Mehemedê Muradan, Mewlidî Zazakî

5- Mela Kamilê Puexî, Mewlidî Nebî

6- Bîlal-Feqî Çolîg, Mewlidê Peyximbêr Qey Tutonê Zazon

7- Abdulkadir Muşekî (Arslan), Mevlid-i Nebît

Nê mewlidan ra oyo ke hîna zaf nam û veng dayo û miyanî şarî de merasîmê mewlidan de waniyeno, mewlidê Mela Ehmedê Xasî yo.

\section{MELA HUSEYNÊ BATEYî Û MEWLIDÊ EY}

\section{Cuye û Eserê Ey}

\section{Cuya Ey}

Her çend derheqê name û tarîxê bîyayîş û wefatê Melayê Bateyî de zaf munaqeşayî viraziyaybî zî goreyê qenaetê mi xebata Doç. Dr. Abdurrahman Adak û M. Xalid Sadînî na mesela bi delîlanê maqûlan zelal kerda. Nê xebatan ra xebata M. Xalid Sadinî de vajêno ke Mela Huseynê Bateyî serra 1680 de dewa Bateyî ke girêdayeyê Hakarî biya la nika girêdayeyê qezaya Beytuşşebab yê Şirnaxî ya de ameyo dinya û 1760 de dinya xo bedelnaya. (Sadinî, 2010: 30) La goreyê qenaetê mi meselayanê winayan de merdim bi îhtiyat hereket bikero û wina tarîxanê qet'iyan ra dûrî bivindero û sey Doç. Dr. Abdurrahman Adakî vajo;

†- No mewlid heta nika sey kitabî nêweşîniyayo, la seba ke yew programê TRTyî de weşaniyayo ma nameye ey zî nuşt. 
peyniya seserra 17. de ameyo dinya û heta nîmeyê seserra 18. cuyayo, hîna maqûl beno. (Adak: 245) Tirba ey dewa ey Bate de ya. Nameyê ey Huseyn û nameyê piyê ey Sofî Mistefa yo. Mexlesê ey zî Bateyî, Melayê Bateyî û Feqîrê Bateyî yê. (Sadinî: 11, 30)

Mela Huseynê Bateyî verê cû hetê Mela Ehmedî de dest bi wendişî kerdo. Mela Ehmed goreyê Doç. Dr. Abdurrahman Adakî, datê Melayê Bateyî yo la goreyê M. Xalid Sadinî, birayê ey o. Dima Medresaya Mîr Zeynel Begê Hekarî de wendişê xo dewam kerdo. Eseranê Melayê Bateyî ra fam beno ke eleqeyêk eyo pêt bi Miks û beganê Miks reyde estbiyo. Hona eseranê Melayê Bateyî ke heta ewro resayê ma ra fam beno ke kurdkî ra teber 'erebkî, fariskî û tirkî zî zanayêne. (Sadinî: 30-31)

Ziwanê Melayê Bateyî, rehet û asan o. Zaf eseranê ey de aseno ke ziwanê ey ziwanê şarî yo. (Sadinî: 35)

\section{Eserê Ey}

Eserê Melayê Bateyî ke heta ewro resayê ma û ma pê hayîdar biyê nê yî: Mewlidname, Zembîlfiroş, Hemaîl û Şî̂rê ey.

\section{Mewlidname}

Esero tewr muhîm yê Melayê Bateyî "Mewlidname" yo. Tarîxê edebiyatê kurdî de, no war de esero tewr verên o ke bi nameyê "Mewlûda Kurmancî" nam û veng dayo. Nê mewlidî ra ver miyanê kurdan de mewlidê erebkî waniyayêne. Labelê nuştişê nê mewlidê kurmanckî ra pey, miyane kurdan de hinî mewlidanê erebkiyan, ca dayo mewlidê kurmanckî. Mewlidnameyê Bateyî hewa verên hetê Haziq Derwîş Nihadê Diyarbakirijî ra serra 1895 de Îstanbul de çap biyo. No nusxe 16 qism û 527 beytî yo. Nusxeyo tewr kehen yê A. Jaba zî 17 qism û 576 beytî yo. (Adak: 250-251) Nusxeyo ke M. Xalid Sadinî kitabê xo de esas girewto û nusxeyo ke Huseyn Şemrexî transkirîbe kerdo zî hetê hûmara beytan ra pênêgînê. Tay beytî yê Sadinî de estê, yê Şemrexî de çin ê. Tay beytî zî yê Şemrexî de estê la yê Sadinî de çin ê.

Nimûne: Yê Sadinî de qismê "Bûna Pêxember"î de beytê 26 û 27. î û qismê "Merheba" de beytê 11., 12., 13 û 21. î, tam şeş beytî yê Huseyn Şemrexî de çin ê. Nusxeyo ke Huseyn Şemrexî tiranskirîbe kerdo de zî qismê "Gaziya Zerreyan Di Dema Çêbûna Pêxember Da (s)" de beyta 18. yê Xalid Sadinî de çin a. Netîce de nusxeyo ke Sadinî girewto 
kitabê xo hûmara beytan 589, nusxeyo ke Huseyn Şemrexî transkirîbe kerdo de hûmara beytan 585 o. Na xebata xo de nusxeyo ke Huseyn Şemrexî, nusxeyê destxetê serra 1824 ya mîladî ra transkrîbe kerdo ma do ey esas bigîrî.

\section{Zembîlfiroş}

No eserê Melayê Bateyî eserêko menzum o. Nusxeyê manzûmeyê Zembîlfiroşî yê Melayê Bateyî, Lenîngiradî de kitabxaneyê Saltikov-Şêdrîn de estê. Nuşteyê ke ewro bi nameyê "Zembîlfiroşa Melayê Bateyî" nusiyayê arêkerdişanê Albert Sosin û Qanatê Kurdoyî ra pêk ameyî. (Adak: 252-253)

\section{Hemaîl}

No eserê Melayê Bateyiyî kurdkî niyo. Erebkî û fariskî nusiyayo. Eserî de derheqê hemayîlî ke merdim xo ra pa keno; derman û tilsimê tay nêweşiyan û faydeyê sure û ayetanê Quranî de malumatî estê. (Adak: 255)

\section{Şûrê Ey}

Mewlidname, Zembîlfiroş û Hemaîl ra teber şî̂rê Melayê Bateyî zî estî. La ey bi xo şî̂rê xo dîwanêke de kom nêkerdî. Nê serranê peyênan de hetê tay cigêrayoxan ra şî̂rê ey ameyê komkerdiş. Mesela Tehsîn Doskî û Muhsîn Doskî, esero ke bi nameyê "Melayê Bateyî Jiyan û Behrem" o de 21 şî̂re, hevdûbêja eya ke Mela Mensûrê Girgaşî reyde û yew texmîsa eya ke beytêka Macîn ser o nuşta kom kerdê. (Adak: 253)

\section{MELA EHMEDÊ XASî Û MEWLIDÊ EY}

\section{Cuye û Eserê Ey}

\section{Cuya Ey}

Mela Ehmedê Xasî 1867 de nehiyeya Hezanî, ke girêdayeya qezaya Licê ya Diyarbekirî de ameyo dinya. Nameyê ey Ehmed o. Seba ke nameyê 'eşîra înan xas biyo tira Ehmedê Xasî vajiyayo. Nameyê piyê ey Hesen o labelê miyanî şarî de tira Mela Hesen û Sofî Hesen zî vajîno. (Malmîsanij, 1985: 75)

Melayê Xasî sey zaf alimanê kurdan, medreseyanê Kurdistanî yê ciya-ciyayan de wendo û perwerdeyê xo yê medreseyî Medreseyê Mesûdiye yê Diyarbekirî de temem kerdo. Memuriye $\hat{\mathrm{u}}$ muderrîsiye ra teber Muftiyiya Licê zî kerdo. (http://www.zazaki.net/haber/ehmed-xas-93.htm, 07 tebax 2009) 
Ehmedê Xasî erebkî, fariskî, tirkî û kurdkî (zazakî, kurmanckî) zanayêne û eserê xo bi nê ziwanan nuştê. Yew şî̂ra eya ke bi 'erebkî derheqê Mustefa Kemalî de nuşta beytêke tira wina ya:

Qîdwetu'l-Etrakî turren el-musemma bî̀'l Kemal

Kane me 'nahû zewalen, fî̀z-zewalîn fì'z-zewal (Malmîsanij: 76)

Seba şî̂ra eya tirkî zî ma eşkenî na şî̂ra ke heşt beytî ya, ci ra di beytan, sey nimûne bidî:

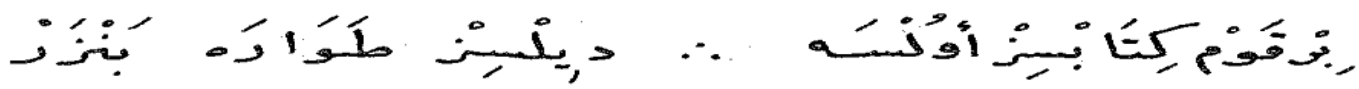

Bir kavm kitabsız olse / Dîlsız tevare benzer

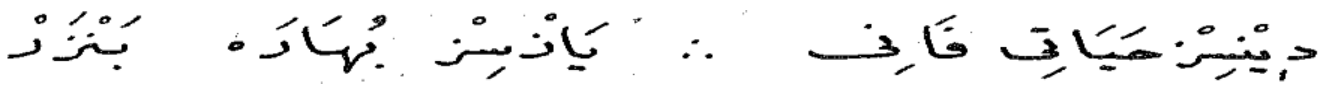

Dînsız hayatî fanî / Yazsız buhare benzer (Xasî, 1986: Qismo Diyin, r.V)

Melayê Xasî, melayêko miletperwer biyo. Meselaya kurdan ser o Ziya Gokalpî dir zaf munaqeşe kerdo. Hetta hîna verî, wextê Sultan Ebdulhemîdî de seba xebata kurdiye, surgunê Girawa Rodosî biyo û şeş mengî wêra de surgun de mendo. (Malmîsanij: 76)

Melayê Xasî, 18 sibate 1951 de Hezan de dinya xo bedelnaya. Mezelê ey Hezan de yo.

\section{Eserê Ey}

Mela Ehmedê Xasî zazakî ra teber kurmanckî, erebkî, fariskî û tirkî zî nuşto. Şaîro netewîyo namdar ê Kurdan Cegerxwîn vano ke Ehmedê Xasî bi zazakî "Cengnameyê Kurdan û Armeniyan" zî nuşto. Labelê no eser heta ewro nêresayo ma. Hona goreyê vatişan Melayê Xasî tay nuşteyê xo dayê nas û merdimanê xo la înan tersê dewleta tirkan ver o ê veşnayî. (Canşad:2011) 
Eserê Mela Xasî yê ke heta ewro çap biyê û ma eşkayî biresî ci nêyî; Mewlidu'n-Nebiyyi'lQurayşiyyi, Kitâbu Büşra'l-İbâdi Fî İlmi'l-İ'tiqâd, Kitab'ut-Tesdîd Bi Şerhi Muxteser'it Tewhîd, Reddiyyetun Lilxâsî, Manzûmetun Qad Cumi'a Fîhâ Esmâullahi'l-Husnâ û şî̂rê ey. (Lezgîn: 2009)

\section{Mewlidu'n-Nebiyyi'l-Qurayşiyyi (Salawâtullahi Aleyhi Fi'l-Bukreti we'l-Aşiyyi)}

Melayê Xasî kitabo kirdkî yo tewr verên Mewlidu'n-Nebiyyi'l-Qurayşiyyi, ke destpêkê Edebiyatê Zazakî hesebîno, 1898 de nuşto, û 25 adare 1899 de Diyarbekir de çapxaneyê Lîtografya de 400 nusxeyê nê mewlidî ginayê çape ro û vila biyê. (Malmîsanij: 49)

Mewlidê Kirdî, hetê çend kesan ra herfanê erebkî ra transkirîbeyê herfanê latînkî biyo. Reya verêne Mehemed Malmîsanijî 1985 de transkirîbe kerdo û Parîs de kovara Hêvî hûmara 4. de weşanayo. Dima 1994 de Mihanî, 2005 de Mela Muhemedê Kavarî, 2008 de W. K. Merdimînî transkirîbe kerdo û çap kerdo. Roşan Lezgînî zî 2009 de transkirîbe kerdo û keyepelê Zazaki.Net de weşanayo, dima zî 2013 de newe ra transkirîbe kerdo û sey kitabî hetê weşanxaneyê Nûbiharî ra çap biyo û weşaniyayo.

Mewlidê Melayê Xasî, hetê tay aliman ra îstînsax biyo û sey nusxeyê destxetî nusiyayo. Nê aliman ra yew zî Mela Zeynelabîdîn Amedî yo. Mela Zeynelabîdîn Amedî, esere Melayê Xasî yê ke kewtê ci dest, îstînsax kerdî û 1986 de sey kitabî Diyarbekir de çap kerdî. Nê kitabî de Mewlidê Melayê Xasî ra teber, mulemmaya Xasî ya ke bi erebkî, fariskî, tirkî, kurmanckî û zazakî nusîyaya, yew xezela tirkî û hîrê eserî ke Melayê Xasî erebkî nuştî; Manzûmetun Qad Cumi'a Fîhâ Esmâullahi'l-Husnâ, Reddiyyetun Lilxâsî, (qismêk nê eserî nesr o, qismêk zî menzûm o) û Kitâbu Büşra'l-İbâdi Fî İlmi'l-İ'tiqâd ca girewto. (Xasî:1986)

\section{Kitâbu Büşra'l-İbâdi Fî İlmi'l-í'tiqâd}

No metn erebkî nusiyayo û metnêko menzûm o. Derheqê baweriya mezhebê Eş’ariyan de yo.

\section{Kitabu't-Tesdîd Bî Şerhî Muxteserî’t-Tewhîd}

No kitab kitabêko erebkî yo û nesr o. Şerhê Kitâbu Büşra'l-İbâdi Fî İlmi'l-İ'tiqâd i yo. 


\section{Raddiyyetun Lilxâsî}

Reddiyyetun Lilxâsî, diwês rîpelî yo. Rîpelo verên û nême ra zafêr yê rîpelê diyinî şeklê nesrî de nusiyayo. Peyniya rîpelê diyinî de hîrê beytî û rîpelê hîrêyinî de zî diwês beytî, pêro piya pancês beytî zî şeklê menzûmî de nusiyayê. Rîpelê çarinî de bi sernameyê "Cewabu Sani li Ba“di Meqalati İsma“îl el-Îs'irdî” yew qesîdeya erebkî esta. Na qesîda 53 beytî ya. No reddiye û na qesîda bi erebkî nusiyayê.

\section{Manzûmetun Qad Cumi'a Fîhâ Esmâullahi'l-Husnâ}

No menzûmeyê Melayê Xasî, neway û new nameyê Homayî ke tira "Esmâul- Husna" vajêno, bi erebkî û hawayêko menzûm nusiyayo. Neway û new nameyê Homayî ke nînan ra tayî: Ellah, Rehman, Rehîm, Quddûs,'Ezîz, Cebbar ûsn., o, 33 beytan de şeklê menzûmî de nusiyayî. No eser, kitabo ke Mela Zeynelabidîn Amedî hedernayo, ê kitabî de qismo verên, rîpelanê 13,14 û 15 . de viyareno.

\section{Şî̂rê Ey}

Qaso ke ma eşkayê tesbît bikerî, eserê ke ma cor de dayî ra teber şeş şî̂rê bîn yê Melayê Xasî estê. Nînan ra yew xezela tirkî, di şîîê erebkî, yew şîira kurmanckî, yew şî̂ra zazakî û yew zî mulemma ya. Cêr de ma do bi dore nê şî̂ran ra nimûne bidî.

Şî̂ra eya kurmanckî kitabê Mihanî de vêrena. Mihanî na şî̂re, fekê Ehmedê Se'dî ra neqil keno. Şî̂re yewendes çarînan ra pêk ameya û murebbe'êk a. (Mihanî, 1994: 44) Sey nimûneyî cêr de di çarînê aye ameyê dayene.

Dirêj ke Xasiya, nezmek cedîde

Di piştî çend selam $\hat{u}$ çend tehiyyat

Li ser Karaziyê ku nav Se'îd e

Dixwîne ew jiber Incîl $\hat{u}$ Tewrat

\author{
Li textê xwe ku rûne Qeyser e ew \\ Li hespê xwe siwar be 'Enter e ew \\ Di seyra roj $\hat{u}$ şev Îskender e ew \\ Bi wechêxwe li Cahiz bûye deh qat
}

Şî̂ra eya zazakî peyniya Mewlidê ey de viyarena. Tena yew beyt a. Şî̂re wina ya:

Ma neqênay henkî behsê emcedî,

Kerdî Mewlûdê Muhemmed Ehmedî 
Şî̂ra eya erebkî, hewt beytî ya. Derheqê Mustefa Kemalî de nusiyaya. Yew beyta na şî̂re Kovara Hêvî de cêrenotê meqaleya "Nimûney Edebiyatê Dimilkiyê Klasîk $\hat{u}$ Dînî" ke Malmîsanijî nuşto de viyarena. Temamê şî̂re kitabê M. Şefik Korkusuz de viyareno. (Korkusuz, 2004: 67) Beyta yewine ya şî̂re wina ya:

Qîdwetu'l -Etrakî turren el-musemma bî’l Kemal

Kane mehnahû zewalen, fî’z zewalîn fî’z-zewal.

Mulemma û xezala tirkî, destxetê Mela Zeynelabidîn Amedî yo ke mewlid û çend eserê bîn yê Melayê Xasî tede nuştî de viyarenê. Xezela tirkî 38 beytî ya. Na xezele ra çend beytî:

Bir qewm kitabsız olse,/ dîlsız teware benzer

Dînsız heyat-î fanî / yazsız buhare benzer

Cehaletın libasî / kîrlî xumare benzer

Nê kitabî de xezela tirkî ra pey, yewna şî̂re yena ke sernameyê aye "Ğazelun Lilxâsî Eydan" o. Herçiqas sername de xezel vajiyabo zî na şî̂re xezel niya mulemma ya. Na şî̂re bi zazakî, kirdaskî/kurmanckî, tirkî, fariskî û erebkî nusiyaya. Her di beytan ra pey yew misra esta. 16 beyt û 8 misrayan ra pêk ameya. Yanî pêro piya 40 misra yê.

Merheben ya men 'ela bil husni teqwîmel beşer

Hafizeş Xaliq şewed ez çeşmi bed nam û nezer

Mûcidi esbab û alat û we ma minha seder

Dil ji qeyda leşkeri ġem kir reha weqti seher

Ah û nalînê verênî, bî vînî nêmend eser

Faqe heqqen şe'nuhu eqranehu min geyri şek

Xatiri maderi pîşmanendê an eshabi sek

Rûhime dîdî rewanim ben de gîtdim qalme tek

Yek bibin ta yek bibînin wek dû çeşmine felek

Husnu xulqi binisbet yê, nisbetê ma xeyr û şer 


\section{MEWLIDÊ MELAYÊ XASÎ DE TESÎRÊ MELAYÊ BATEYÎ Û MEWLIDÊ EY}

\section{Hetê Şeklî Ra Wekenitişê Mewlidê Bateyî}

Mewlidê Melayê Bateyî sey heme mewlidan mesnewiyêk o. Nusxeyo ke ma xo rê esas girewto newês qism û 585 beytî yo. Peymeyê heceyê ci yewendes hece yo. Qaliba eruzî "Fa'ilatun, Fa'ilatun, Fa'ilun" o. Qafiyeyê ey, seba ke mewlid mesnewî ra bêjêk o; aa, bb, $\mathrm{cc}, \ldots$ yo.

Nusxeyê Huseyn Şemrexî ke ma xo rê esas girewto de misrayanê tay beytan de peymeyê heceyî û qaliba erûzî de tay qusûrê qitekî estê. Tay misrayî des heceyan ra tay zî diwês heceyan ra pêk ameyî.

Nimûne:

"Bi eşq $\hat{u}$ şewqek hûn bibêjin: es-selat" $\rightarrow$ na misra diwês hece ya.

"Karwan hat $\hat{u}$ hemî em çûne mal" $\rightarrow$ na misra des hece ya.

Seba qusûrê qaliba erûzî zî ma eşkenê na misra nimûne bidî:

"Bi eşq û şewqek hûn bibêjin: es-selat"

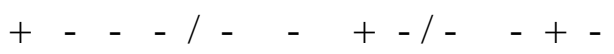

Na misra de zî seke aseno, qaliba mewlidî, ke Fa'ilatun, fa'ilatun, fa'ilun a, pê nêgîna. Hetê qalibe ra misrayêka qusûrin a.

Hona nê metnê pîrozî de ma raştê îmale û zihafî̀ zî yenê. Seba nimûneyî ma eşkenî beyta destpêkî binawnî.

Hemdê bê hed bo Xwedayê 'alemîn / Ew Xwedayê daye me dînê mubîn +- - I - + - I - + - I - + - I + - - I- + - 
Seke cor de aseno misraya yewine ya na beyte de heceyê dê de zihaf û misraya diyine, heceyê me de zî îmale esto. (Adak: 26)

La nê qusûrî qusûrê muhîmî niyê. Çunke Edebiyatê Klasîk de qusûrê winayinî normal hesibînê. Ganî nêro vîra kerdene ke edebiyatê klasîk de ma eşkenî eseranê şaîranê tewr serkewteyan de zî raştê qusûranê weznî yê winayînan bêrî.

Seba ke qalibî de qusûr nêviraziyo, çend cayan de ma raşt ameyê ke Melayê Bateyî, çekuyê ke hîna zaf lehçeyê zazakî de gureniyenî zî gurenayî. Ê zî qismê Munacatî de nê beytanê cêrênan de wina vêrenî.

Nimûne:

Nê tu xeffar î $\hat{u}$ settarê 'uyûb / Ma bibexşî $\hat{u}$ bixufranî zunûb

Na beyt a ke qismê Du'a de viyarena de herinda zemîrê me yê kurmanckî de zemîrê ma yê zazakî gureniyayo.

Ziwanê mewlidî de her çend kelîmeyê erebkî û fariskî estbî zî kê eşkenî bi hawayêko pêroyî vajî ziwanêko asan o, û rehet fam beno.

\section{Hetê Şeklî Ra Wekenitișê Mewlidê Xasî}

Mewlidê Melayê Xasî zî sey mewlidê Melayê Bateyî û mewlidanê bînan mesnewî yo. No mewlid, transkirîbeyê Roşan Lezgînî ke ma xo rê esas girewto de, çarês qismî û 366 beytî yo. Peymeyê heceyê ci yewendes hece yo. Qaliba eruzî "Fa'ilatun, Fa'ilatun, Fa'ilun" o. Qafiyeyê ey, sey heme mesnewiyan; aa, bb, cc,... yo.

Nusxeyo ke Roşan Lezgînî transkirîbe kerdo de misrayanê tay beytan de peymeyê heceyî û qaliba erûzî de tay qusûrê qitekî estê. Tay misrayî des heceyan ra tay misrayî zî diwês heceyan ra pêk ameyî.

Nimûne:

7/b Dest $\hat{u}$ ling $\hat{u}$ piya bi e 'ezayê bînan $\rightarrow$ na misra seke asena 12 hece ya.

50/a Yew bido yew dirheme bi qelbu şedîd $\rightarrow$ na misra zî 12 hece ya. 
Nê di misrayan û sey nînan çendêna misrayan de hem hetê heceyî ra hem zî hetê qalibe ra qusûrê qitekî estê. La seke ma cor de zî vatibi, nê qusûrî, edebiyatê klasîkî de xayet normal ê.

Adnan Oktay her çend meqaleya xo de vano ez metnê Melayê Xasî de raştê med û zihafî nêameya zî, (Oktay, 2011: 7) labelê xebatê xo de ma dî ke metnê mewlidî de senî ke îmaleyî estê, med û zihafî zî estê.

Nimûne:

6 Her nefes de vacê, hemd û şukri to. / Wacib o bêşubhe ancî heqqi to

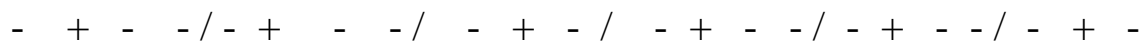

Na beyte de misraya yewine de heceyê "cê" de zihaf û misraya yewine de "de" de zî îmale esto. Tiya de misraya diyine de çekuya "wacib o" de zî wesl esto. Misrayê cêrênî ke qismê çarin û heştin de viyarenê de zî çekuyanê "kerd" û "mend" de med esto.

154/a Kerd[i] emrikew letîf 'ilmi xo de.

204/a Mend[i] 'Ebdullah tenê yo xanedan

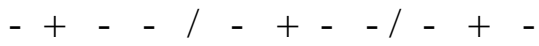

Metnê Mewlidê Melayê Xasî de çekuyê erebkî û fariskî bibê zî bi hawayêko pêroyî çekuyê sadeyî hîna zaf gurêniyayê. Xora cekuyê ke erebkî û fariskî yê zî, miyanî şarî de yenê gurênayene. Sey çekuyanê bismillah, raziq, hemd, şukr, ezel, ebed, miskîn, qelb, şafî, şeytan, dîn, şah ûsn. Coka wexto ke merdim hewl bala xo bido û biwano û rind bigoştaro weş fam beno.

Mewlidê Xasî, hetê gurênayîşê huneranê edebiyan ra zî metnêko xayet zengîn o. Hunerê Edebiyatê Klasîk yê sey qafiye, redîf, tekrîr, cînas, nîda, îstîfham, mecaz, teşbîh, îstîare, teşhîs, îqtîbas, tezat, tenasûb ûsn. zaf hunerî bi hostayî ameyê gurênayene. (Oktay: 1315) 
Nimûne:

Çende rey bê masîwa bi hemdi ma / Labelê nêrî hisaban çendi ma

Key şima dî nameyê şahê şima / Ame vatiş, sunnet o, vacê şima

Rebbi hemd $\hat{u}$ şukrî ancax to ri bê / Kîbr $\hat{u}$ medh $\hat{u}$ fexrî pêro to ri bê

Key yeno ca Rebbî, heqqê şukri to? / Ger ezel ra ta ebed ma zikri to

Seke beytanê corênan de aseno, beyta yewine de çekuyanê hemd û çend de vengê "d" de qafiye û $\underline{\mathbf{i} \text { ma }}$ de redîf, çekuyanê çende û çendi de cînas, beyta diyine çekuyanê şima de tekrîr, beyta hîrêyin de çekuya Rebbi de nîda, beyta çarine de çekuya Key de îstîfham esto.

Senî ke Mewlidê Melayê Bateyî de ma vatibi Melayê Bateyî, tay çekuyê ke hîna zaf zazakî degureniyenî gurenayî, eynî wina Melayê Xasî zî tay çekuyê ke hina zaf kurmanckî de yenê gurenayene, mewlidê xo de gurenayî. Mavajî herinda çekuya coka de loma, herinda Homa de Xuda, herinda darey de das ûsn.

\section{Hetê Muhtewa Ra Wekenitişê Mewlidê Bateyî}

Mewlidî, edebiyatê klasîk yê dînî de bêjêk ê. Derheqê pêxemberê musulmanan Hz. Muhemedî (s) de nuşteyê manzûm ê. No semed ra Mewlidê Bateyî zî biyayîşê Hz. Muhemmedî û hedîseyê ke Ey dir eleqedar ê bi hawayêko menzûm û wecîzane ameyê nuştiş. Newês qismê nê mewlidê kurmanckî, bi hemd û şikrê Homayî dest pêkeno û bi dore pesnê pêxemberî, xêrê wendişê mewlidî, xeleqnayîşê nurê pêxemberî, xeleqnayîşê $\mathrm{Hz}$. Ademî, întiqalê nurê pêxemberî, weladetê piyê pêxember 'Ebdullahî, seba kiştişê piyê pêxemberî 'Ebdullahî pêkerdişê cihûyan, zewacê 'Ebdullah û Amîne, seba hemla Amîne mizgîndayîşê pêxemberan û wefatê 'Ebdullahî, weladetê pêxemberî, gama biyayîşê pêxemberî de vengdayîşế zerreyan, mûcîzeyê ke şewa biyayîşê pêxemberî de ameyê meydan, nîşanê ke bawkalê pêxemberî wextê biyayîşê pêxemberî de diyî, seba şitdayîşî pêxemberî ameyîşê Helîma bi Mekke, miyanê Qebîleyê Se'diyan de hedîseyê ke pêxemberî ra sudûr biyê, agêrayișê Helîma ke pêxemberî Mekke de teslîmê Amîne bikera dewam keno û peynî de zî bi dua qediyeno. 


\section{Hetê Muhtewa Ra Wekenitişê Mewlidê Xasî}

Mewlidê Xasî zî sey Mewlidê Bateyî bi hemd û şukrê Homayî û pesindayîșê Hz. Muhemmedî dest pêkeno. Dima qismo diyin de bi behsê tertîbê mewlidî û fazîletê wendişê mewlidî dewam keno. Çarês qismanê mewlidî de bi dore çinbiyayîşêe eşyan û sirrê Homayî, xelqê pêxemberî û xelqê eşyan, emrê Homayî qey qeleme, xelqê Ademî û nurê pêxemberî yo ke kewto paştey ey, cennetî ra eştişê Ademî û mardişê kalikanê pêxemberî, Abdullahî rê waştişê Amîna û cihûyê ke wazenî Abdullahî bikişî, întiqalê nurê pêxember û hewnê ke Amîna diyî, welednayîşê pêxemberî, 'eceyîbê (mûcîze) ke şewa biyayîşê pêxemberî de ameyî meydan, Helîmaya Se'diyan ke heta hîrê serrî pêxember weye kerdo, nuzûlê wehyî û mîrac û qismo peyên de zî duaya mewlidî bi hawayêko edebî û wecîzane ardî ziwan.

\section{Her Di Mewlidan De Hetê Ke Pêmanenî}

Heme çî ra ver, nê her di mewlidî, tarîxe edebiyatê kurdî de mewlidê tewr verên î ke ameyê nuştiş. Gerek kurmanckî de gerek zî zazakî de zaf mewlidî nusiyayê la nînan ra êyê ke miyanê şarî de tewr zêde rexbet diyo û meşhur biyê, kurmanckî de mewlidê Melayê Bateyî û zazakî de zî mewlidê Melayê Xasî yo.

Pêymeyê heceyê nê her di mewlidan zî 11 (yewendes) heceyin o. Seke ma cor de zî vatibi qaliba erûze, her di mewlidan de zî "Fa'ilatun, Fa'ilatun, Fa'ilun" a.

Tablo: Sername û babetê ke mewlidê kurmanckî û zazakî de viyarenî.

\begin{tabular}{|c|c|c|c|c|}
\hline \multirow[b]{2}{*}{ 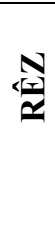 } & \multicolumn{2}{|c|}{ MEWLIDÊ MELAYÊ BATEYÎ } & \multicolumn{2}{|l|}{ MEWLIDÊ MELAYÊE XASÎ } \\
\hline & Sername û Babetê Qismî & $\begin{array}{l}\text { Numreyê } \\
\text { Qismî }\end{array}$ & Sername û Babetê Qismî & $\begin{array}{l}\text { Numr } \\
\text { eyê } \\
\text { Qismî }\end{array}$ \\
\hline & Hemdê Xwedê & 1 & $\begin{array}{l}\text { Mewlidun-Nebiyyî-l Qureyşiyyî (Hemd û } \\
\text { şukrê Homayî û pesnê Pêxemberî yo) }\end{array}$ & 1 \\
\hline & Pesnê Pêxember (s) & 2 & $\begin{array}{l}\text { Mebhesê Tertîbê Mewlidî û Fedley } \\
\text { Wendişî }\end{array}$ & 2 \\
\hline & Xêra xwendina Mewlûdê & 3 & $\begin{array}{l}\text { Mebhesê Çinbiyayîşê Eşyan û Sirrê Homa } \\
\text { Yo }\end{array}$ & 3 \\
\hline
\end{tabular}


ISSUE NO. 1 ( 2015/1)

\begin{tabular}{|c|c|c|c|c|}
\hline & Afirandina nûra pêxember (s) & 4 & $\begin{array}{l}\text { Mebhesê Xelqê Peyxemberê Ma û Xelqê } \\
\text { Eşyan o }\end{array}$ & 4 \\
\hline & Afirandina Adem (e) & 5 & Mebhesê Emrê Homa yo Qey Qeleme & 5 \\
\hline & Întîqala nûra Pêxember (s) & 6 & $\begin{array}{l}\text { Mebhesê Xelqê Ademiy û Nurê } \\
\text { Peyxemberî yo Kewti Paştey Yê }\end{array}$ & 6 \\
\hline & Wîladeta 'Ebdullah bavê Pêxember (s) & 7 & $\begin{array}{l}\text { Mebhesê Eştişê Ademî yo Cennet ra û } \\
\text { Mardişê Peyxemberê Ma wo }\end{array}$ & 7 \\
\hline & $\begin{array}{l}\text { Peymanbestina Cihûyan a ji bo kuştina } \\
\text { 'Ebdullah }\end{array}$ & 8 & $\begin{array}{l}\text { Mebhesê 'Ebdullahiy û Cuhûdê Şamiyan o } \\
\text { û Waştişê Amîne Ci rê }\end{array}$ & 8 \\
\hline & Zewaca 'Ebdullah û Amîneyê & 9 & $\begin{array}{l}\text { Mebhesê Intiqalê Nûrê Peyxemberiy û } \\
\text { Hewnanê Amîna yo (r) }\end{array}$ & 9 \\
\hline 0 & $\begin{array}{l}\text { Mizgîndana Pêxemberan li Amîneyê ji } \\
\text { bo Hemlê wê û Wefata 'Ebdullah }\end{array}$ & 10 & $\begin{array}{l}\text { Mebhesê Welednayîşê Peyxemberê Ma wo } \\
\text { (s) }\end{array}$ & 10 \\
\hline 1 & Hatina wextê wîladeta Pêxember (s) & 11 & $\begin{array}{l}\text { Mebhesê Henî 'Eceyîban o Amey Wucûd } \\
\text { Şewê Mewdûdî }\end{array}$ & 11 \\
\hline 2 & $\begin{array}{l}\text { Gaziya zerreyan di dema çêbûna } \\
\text { Pêxember da (s) }\end{array}$ & 12 & Mebhesê Helîmay Se’diyan o (r) & 12 \\
\hline 3 & $\begin{array}{l}\text { Mûcîzeyên ku di şeva wîladetê } \\
\text { Pêxember da çêbûne }\end{array}$ & 13 & Mebhesê Nuzûlê Wehy o û Mî’racî wo & 13 \\
\hline 4 & $\begin{array}{l}\text { Nîşanên ku 'Ebdulmuttelib di dema } \\
\text { wîladeta Pêxember da dîtiye }\end{array}$ & 14 & Du'au Mewlidin-Nebyyî (s) & 14 \\
\hline 5 & $\begin{array}{l}\text { Hatina Helîmeyê bi bal Mekkehê ji bo } \\
\text { şîrdana Muhemmed (s) }\end{array}$ & 15 & & \\
\hline 6 & $\begin{array}{l}\text { Di nav qebîleya Se’diyan da waqi'eyên } \\
\text { ku ji Pêxember çêbûne }\end{array}$ & 16 & & \\
\hline 7 & $\begin{array}{l}\text { Vegera Helîmeyê bi bal Mekkeyê ji bo } \\
\text { teslîmkirina Pêxember li Amîneyê }\end{array}$ & 17 & & \\
\hline 8 & Munacat & 18 & & \\
\hline 9 & Du’a & 19 & & \\
\hline
\end{tabular}

Seke tabloyê corênî de zî aseno, sey heme metnanê dîniyan nê her di mewlidan de zî qismo verên bi hemd û şukrê Homayî dest pêkerdo û dima zî bi pesnê pêxemberî dewam kerdo. Her di mewlidan de qismê xeyr û fezîletê wendişê mewlidî, xelqê Adem û nurê pêxemberî, întiqalê nurê pêxemberî, 'Ebdullahî re waştişê Amîne, behsê Cihûdê ke wazenî 
'Ebdullahî bikişî, welediyayîşê pêxemberî, ecayîbê (mûcîze) ke şewa biyayîşê pêxemberî de ameyî meydan, behsê Helîmaya Se'diyan û peynî de zî duaya mewlidî esta.

Nê her di mewlidan de senî ke nê behsê ke ma cor de rêz kerdî pêmanenî, tay beytî estî ke hema hema kê eşkenî vajî mota-mot eynî yê. Ma vajî Mewlidê Bateyî de qismo diwêsin o ke sernameyê ey "Gaziya Zerreyan Di Dema Çêbûna Pêxember da (s)" de beyta diyine wina ya:

Merheba ey sirrê furqan merheba / Merheba dermanê derdan merheba

Mewlidê Xasî de qismo desin o ke sernameyê ey "Eno Mebhesê Welednayîşê Peyxemberê Ma wo (s)" de beyta yewendesine wina ya:

Merheba ey sirrê subhan berheba / Merheba ey rûhê rûhan merheba

Hona Mewlidê Bateyî de eynî qismî de beyta hewtine wina ya:

Merheba ey rehmeten lîl'alemîn / Merheba hatî şefí 'ulmuznibîn

Mewlidê Xasî de eynî qismî de beyta hewtêsine zî wina ya:

Merheba ey rehmeten lîl'alemîn / Merheba ya men şefí'el muznibîn

\section{Her Di Mewlidan De Hetê Ke Pênêmanenî (Cêra Ciyayî)}

Mewlidê Bateyî de tay qismî estî ke Mewlidê Xasî de ê qismî çin ê. Eynî wina, Mewlidê Xasî de zî tay qismî yê Mewlidê Bateyî de çin ê.

Eke ma bala xo bidî tabloyê corênî, ma do bivînê ke qismê ke Mewlidê Bateyî de estê la Mewlidê Xasî de çin ê nê yî: Wîladeta 'Ebdullah bavê Pêxember (s), Mizgîndana Pêxemberan li Amîneyê ji bo Hemlê wê û Wefata 'Ebdullah, Nîşanên ku 'Ebdulmuttelib di dema wîladeta Pêxember da dîtiye û Munacat. 
Qismê ke Mewlidê Xasî de estê la yê Bateyî de çin ê zî nê yê: Mebhesê Tertîbê Mewlidî, Mebhesê Çinbiyayîşê Eşyan û Sirrê Homa Yo, Mebhesê Çinbiyayîşê Eşyan û Sirrê Homa Yo, Mebhesê Xelqê Peyxemberê Ma û Xelqê Eşyan o, Mebhesê Eştişê Ademî yo Cennet ra û Mardişê Peyxemberê Ma wo, Mebhesê Nuzûlê Wehy o û Mî’racî wo.

\section{ENCAM}

Na xebate de seba Mewlidê Bateyî, transkrîbeyê Huseyn Şemrexî û seba Mewlidê Xasî zî transkrîbeyê Roşan Lezgînî esas ameyo girewtene. Seba ke na xebate wextêko zaf teng û kilme de ameya hedernayene nêeşkiyêno vajiyo wekenitişêko bê qusûr o. Coka hewceyo ke nê warî de cigêrayîşêko hîna hîra bêro kerdene. Eke cigêrayîşêko wina bi teferuat û hîra bêro kerdene, do encamê hîna balkêş vejiyê orte. Na xebate de ame diyene ke nê di mewlidan de hetê ke pêmanenî zaf ê. Hetta seke cor de ameyê nîşandayîş, Mewlidê Melayê Xasî de tay beytî estî ke kê vanî qey Mewlidê Bateyî ra kopî biyê yan zî kurmanckî ra çarniyayê zazakî. Naye ra fam beno ke Melayê Xasî bin tesîrê Melayê Bateyî û mewlidê ey de mendo. La no nêno a mena ke mewlidê Melayê Xasî, tercume yan zî teqlîdê Mewlidê Melayê Bateyî yo. Çunke seke cor de qismê hetan ê ciyayan de ame diyene, Mewlidê Xasî de tay meseleyî estê ke Mewlidê Melayê Bateyî de çin î. No zî nawneno ke Mewlidê Xasî, teqlîd yan zî tercume niyo.

Xora Edebiyato Klasîk yê Zazakî, miyanê Edebiyatê Klasîk yê Kurdan de edebiyato tewr erey kewte yo. No semed ra bin tesîrê eseranê xo ra verênan ê kurdkî de mendişê ci, xayet normal o.

Rohat Alakom meqaleyêka xoya kurmackî de wina vano: "Ziman û edebiyata ku me winda kiribû, mele û medreseyan şunda dane me!” (Alakom, 2013: 64) Yanî: ziwan û edebiyato ke ma vindî kerdibi, mela û medreseyan peyser dayo ma! Ma zî na qala weşe ser o, sey vateyê peyênî vanî ke xora o edebiyat zî medreseyan de hetê melayan ra peyda bibi. Ma minetdarê ê melayanê erjayeyan ê. Homa hemîne ra razî bo û cayê înan cenet bikero. 


\section{ÇIMEYî:}

Adak, Abdurrahman: Edebiyata Kurdî Ya Klasîk-II, Notê Derse, Mêrdîn, 2013

Alakom, Rohat: “Dildarekî Gotina Nivîskî Mehmed Emîn Bozarslan”, Nûbihar, h. 123, Bihar, Îstanbul, 2013

Altun, Dr. Mustafa: “Aruz Ölçüsünün Bazı Özellikleri”, http://www.dilbilimi.net/aruz_olcusu.pdf, Ağustos 2013

AÖF Ders Özetleri Serisi, "Eski Türk Edebiyatına Giriş: Biçim ve Ölçü Dersi Özeti”, http://www.dersnotlarin.com/eski-turk-edebiyatina-giris-bicim-ve-olcu-ders-ozeti/, 04 Ocak 2013

Bateyî, Mela Huseyn: Mewlûd, çar. Huseyn Şemrexî, Weşanxaneyê Nûbiharî, Îstanbul, 2011

Canşad, Murad: "Mewlidê Kirmanckî", http://www.zazaki.net/yazi/mewlid-kirmanck-136.htm, 26 Sibat 2011

Ezîzan, Herekol: "Klasîkên Me, An Şahir û Edîbên Me Ên Kevin”, Hawar, h. 33., Oktobre, Șam, 1941

Kızıl, Hayrettîn: "Diyarbakır ve Çevresinde Yazılmış Mevlitlerin Konularına Göre Tasnifi Denemesi”, e-Şarkiyat İlmi Araştırmalar Dergisi, Sayı: VII, http://e-sarkiyat.com/makaleler/7.sayi/6.pdf, Nisan, 2012

Korkusuz, M. Şefik: Tezkîre-i Meşayih-i Amid (Diyarbekir Velileri) I-II, Weşanxaneyê Kentî, 2004

Lezgîn, Roşan: "Mewlidê Kirdî”, http://www.zazaki.net/haber/mewlid-kird-57.htm, 05 tebaxe 2009

Malmîsanij, Mehmed: "Nimûney Edebiyatê Dimilkiyê Klasîk û Dînî” Hêvî, H. 4, Îlon, Parîs, 1985

Mihanî: Mewlûdê Nebî (Bİ ZIWANÊ KURDÎI (ZAZAKÎ), Weşanxaneyê Firatî, Îstanbul, 1994

Oktay, Adnan: "Klasik Edebiyat Teknikleri ile Bir Değerlendirme: Melaye Ehmedê Xasî’nin Kirmanca (Zazaca) Mevlidi”, Internasyonal Conferance on Zaza Studies: The Zaza People: History, Language, Culture, Identity, 28-30 October, 2011, Yerevan, Armenia 
Sadinî, M. Xalid: Mela Huseynê Bateyî Jiyan, Berhem î Helbestên Wî̀, Weşanxaneyê

Nûbiharî, Îstanbul, 2010

Saraç, Prof. Dr. M.A. Yekta: Klasik Edebiyat Bilgisi (Biçim, Ölçü, Kafiye),

Weşanxaneyê Gökkubbe, ç. 6., İstanbul, 2012

Tiraşçı, Mehmet "Cizre ve Çevresinde Kürtçe Mevlitler ve Müzikal Olarak Günümüzde

İcra Edilmiş Tarzları", Bilim Düşünce ve Sanatta Cizre, ed. M. Nesim Doru, Mardin Artuklu Üniversitesi Yayınları, İstanbul, 2012

Xasî, Mela Ehmed: Eserê Melayê Xasî, amd. Zeynelabidîn Amedî, Weşanxaneyê

Diyarbekirî, 1986

Xasî, Mela Ehmed: Mewlidê Kirdî, amd. Roşan Lezgîn, Weşanxaneyê Nûbiharî, İstanbul, 2013

Xasî, Mela Ehmed: Mewkûdê Nebî, çar. Mihanî, Fırat Yayınları, Îstanbul, 1994

Xasî, Mela Ehmed: Mewlîd, çar. W. K. Merdimîn, Weşanxaneyê Hîvda, Îstanbul, 2008

Yergin, Mehmet: “Zazakî de Metnê Dînî”, Nûbihar, h. 119, Îstanbul, 2012

Zazakî.Net: "Ehmedê Xaŝ̂”, http://www.zazaki.net/haber/ehmed-xas-93.htm,

07 Tebaxe 2009 